\title{
Predictive Skills and Reading Efficiency of College English Based on Multimedia Technology
}

\author{
Yuexia Ding and Ping Li 1 \\ Foreign Language School, Weifang University, Shandong 262100, China \\ Correspondence should be addressed to Ping Li; chunfenghuayuli@163.com
}

Received 23 December 2021; Revised 7 January 2022; Accepted 8 January 2022; Published 31 January 2022

Academic Editor: Tongguang $\mathrm{Ni}$

Copyright (c) 2022 Yuexia Ding and Ping Li. This is an open access article distributed under the Creative Commons Attribution License, which permits unrestricted use, distribution, and reproduction in any medium, provided the original work is properly cited.

\begin{abstract}
Slow reading speed is a common problem among Chinese college students' English learning, limiting the amount of reading done and thus directly affecting English-level improvement. Teachers in English classes place a premium on improving students' reading skills but the results are not immediately apparent. Even if many students have strong vocabulary and grammar skills, they will never be able to read English fluently. Teachers should prioritize not only students' knowledge acquisition and intelligence development but also the development of students' interpersonal skills and emotional intelligence in order to maximize their potential. This paper uses multimedia technology to investigate the role of multimedia technology in improving college Englishreading efficiency and analyzes how teachers and students can play a positive role in improving the efficiency of college multimedia teaching using data mining technology, which shows that students' predictive reading skills can help them improve their reading efficiency. Teachers can also supervise and ask questions about students' learning progress via computers, communicate effectively with students, and provide timely feedback on students' learning results using multimedia technology.
\end{abstract}

\section{Introduction}

The rapid development of the economy and society is inextricably linked to the advancement of teaching activities and the innovation of teaching methods. Multimedia has permeated primary and secondary school classrooms in most areas as IT has matured, from tape recorders, slides, and physical projectors in the 1990s to today's network equipment, liquid crystal screens embedded on blackboards, and so on [1]. Teachers' teaching concepts and students' learning concepts both change as teaching media technology evolves [2]. As a result, we must improve the quality of teaching in the interaction between teachers, students, and the media. The positive role of teachers and students in transforming the benefits of multimedia teaching into the benefits of teaching quality is critical. Traditional teaching content and methods are insufficient to meet the demands of modern higher education, necessitating fundamental changes [3]. The traditional basic theory should be retained within the specified class hours, while new content should be increased, and the contradiction between more content and fewer class hours is becoming increasingly apparent [4]. Multimedia has become widely used in College English Teaching (CET) as a result of the advancement of computer technology and the popularization of scientific and technological applications, as well as the deepening of English teaching reform [5]. Realizing the informatization of teaching content, the strategization of teaching processes, the modernization of teaching means, and the networking of teaching resources to improve educational quality and promote the all-round development of students' mind and body quality has become the torrent of the general trend of English education [6].

Cultivating strong reading ability is always the primary task of CET. Its purpose is to enable students to use English as a tool to obtain the required professional information [7]. Educational informatization is the core feature of educational modernization, which means making full use of multimedia network to develop education in the information environment 
[8]. With its outstanding advantages, multimedia teaching mode has been unanimously recognized by the majority of teachers and students. Nowadays, universities and even high schools begin to use multimedia technology to carry out teaching work. Although multimedia technology has been applied in teaching for many years, it has not reached the expected goal in terms of teaching efficiency and effect [8]. The core task of educational informatization is to build information-based educational resources. Under the guidance of scientific teaching mode, use information-based teaching means to cultivate excellent information-based talents needed by the society and develop educational informatization industry [9]. The problem of slow reading speed is common among Chinese college students' English learning. It restricts the amount of reading and directly affects the improvement of English level [10]. Based on multimedia technology, this paper studies the role of multimedia technology in improving college English-reading efficiency, analyzes how to give full play to the positive role of teachers and students to improve college multimedia teaching efficiency, and explains the role of students' prediction skills in reading in improving their reading efficiency.

In ordinary English teaching, teachers also attach importance to the improvement of students' reading ability, but the effect is not obvious. The result is that although many students have considerable vocabulary and grammar skills, they cannot become a fluent English reader [11]. For reading, efficiency is therefore important but speed is also another standard to measure reading ability [12]. Teachers recognize that a single language analysis and skill training cannot meet students' English needs, and they begin to prioritize the development of students' comprehensive ability to use English [13]. They also begin to prioritize the research of new teaching strategies, the change of traditional methodology, and the cultivation of students' comprehensive ability to use English. To ensure the normal operation of social order, informatization talents make full use of educational informatization resources to develop and improve informatization laws, regulations, and policies [14]. The educational cause is constantly developing, and the level of educational informatization is gradually improving in a virtuous educational cycle. Multimedia technology aids in the memorization and storage of educational material. It can store a large amount of teaching data, including various types of teaching content, test questions, statistical data, and so on, and it can be accessed by teachers and students at any time [15]. Multimedia technology can be used in the classroom to create an on-site teaching environment, make students feel immersed, not only increase students' interest but also help them understand and master knowledge, and improve teaching effectiveness [16].

The following is how the rest of the paper is structured: Sections 2 and 3 review the study's related work, Sections 3 and 4 describe the paper's methodology, Section 5 presents the experimental results and analysis, and Section 6 summarizes the findings.

\section{Related Work}

Teachers in traditional classrooms frequently attempt to accomplish this goal by carefully preparing the introduction or reading the text aloud. Students can be quickly immersed in the situation related to the artistic conception of the text using multimedia to play a piece of music or an image related to the artistic conception of the text. Silence can be turned into sound, complexity into simplicity, micro into macro, and abstraction into image with multimedia teaching, resulting in the best teaching environment and arousing students' strong learning interest. According to Bai [17], there are two basic criteria for evaluating classroom teaching optimization. One is the effect standard, which states that each student has attained the highest level of teaching, education, and development that he was capable of achieving during this time period. In a college English-listening class, Yao and Scheepers [18] use fragmented learning based on multimedia technology. Ma [19] conducted a feasibility study on multimedia-based college reading learning. By combining students' purposeful fragmented learning with teachers' classroom teaching, Proctor et al. [20] provide an empirical study on the integration of IT and English curriculum. Richards-Tutor et al. [21] used data mining (DM) technology to analyze the online learning process, laying the groundwork for mobile personalized learning research using DM technology. You et al. [22] develop an open-source adaptive hypermedia system through adaptive navigation support and adaptive presentation technology, establishes a user model based on the user's cognitive level and user's access status data, and users can set the rules of their own user model to realize adaptive recommendation of learning content and navigation. Gottardo et al. [23] propose to mark learning content, learner model, and learning strategy with metadata marking method, so as to formulate adaptive learning rule engine. Reading teaching is that students learn one text after another on the basis of literacy, and its ultimate goal is to make students become independent readers and masters of learning [24]. The research on teaching strategies and teaching effects of multimedia-assisted resources is abundant, and the effect of multimedia-assisted teaching is fully affirmed. However, there are still a few teachers who cannot give full play to the auxiliary role of multimedia-assisted resources, and more efforts should be made in the training of teachers using multimedia-assisted teaching resources and the autonomous learning of students using auxiliary resources. Based on DM technology, this paper dynamically tracks the learning behavior and records the learning track in real time and then analyzes the positive significance of multimedia for improving college English reading efficiency.

\section{Characteristics of Multimedia Teaching}

Multimedia teaching that incorporates computer and network technology can not only complement traditional teaching but also provide benefits that traditional teaching cannot. The ability to optimize classroom teaching is 
becoming increasingly apparent thanks to modern multimedia technology. The development of people, particularly the development of personality, is at the heart of optimization theory. Text, pictures, sounds, images, and other different media information are all combined in multimedia teaching, making it more concrete and vivid than traditional blackboard or single media teaching [25]. The task of comprehensively solving the tasks of students' academic achievement, language practical application ability, and intelligent development is at the heart of CET optimization. Dealing with the relationship between time, energy consumption, and educational effect is the key to success. Multimedia technology's main purpose is to present various types of information to students, such as words, images, and sounds, using computer technology and automation technology, which is a new modern teaching method. Traditional teaching methods cannot be realized solely from this perspective. The reform of traditional teaching methods will greatly improve current education and teaching efficiency precisely because of the obvious advantages of multimedia teaching in these aspects.

You can prepare and make courseware in advance as a teacher during lesson preparation. As a student, I sometimes have trouble hearing the teacher's questions clearly, and my notes are incomplete or absent-minded. The use of multimedia technology can also help to improve the effectiveness of instruction. Multimedia instruction is a type of audio-visual instruction. It can attract students' attention and improve students' interest in learning through an effective combination of pictures and sounds, resulting in the best teaching effect [26]. As a result, multimedia technology is closely linked to improving classroom teaching. Multimedia teaching makes use of a computer network's connection point, allowing teachers and students to communicate with each other outside of the classroom at any time and from any location. In comparison to traditional single-mode teaching, multimedia teaching fundamentally alters traditional methodology by making the teaching process multidimensional, integrated, and interactive, which aids students in understanding and remembering the content and improves the teaching effect.

\section{Application of Multimedia Technology in Reading Teaching}

4.1. Enrich Reading Teaching Resources. Multimedia expands the breadth of reading teaching resources. The understanding of the article cannot be interpreted only from the text itself. Only through the introduction of the author's life and writing background, the comparison of related articles and the comments of others can we grasp the text from a higher angle. A courseware is like a movie, and it is often easier to design an excellent script because of the accumulation of teaching plans for many years. However, how to embody the intention and teaching ideas of scripts in courseware is not so easy, which is why the courseware written by a professional software designer according to the teacher's teaching plan often fails to achieve satisfactory results [27]. One-way communication of too many perceptual materials can strengthen stimulation, but it is also easy to cause sensory fatigue, which in turn leads to inhibition.
Students are the main body of classroom teaching. In teaching activities, students' active thinking activities are the guarantee that the cognitive process can be effectively completed. Teachers should make effective use of the technical features of multimedia, such as expressiveness, controllability, and participation to guide students to participate actively.

In traditional teaching, English teachers only have limited resources for teaching reference and accumulated knowledge by themselves, and students can involve fewer resources. The process of resource sharing is often one-way. Multimedia teaching has completely broken this limitation. Teachers and students are faced with a great deal of relevant knowledge. Students have the ability to collect the resources related to texts in advance and do more extensive reading after class. The core elements and relationships of the model of co-creation and communication of multimedia educational resources are shown in Figure 1.

Multimedia teaching is the future development trend in education and teaching methods, and the quality of instruction will inevitably improve, with students being the primary beneficiaries. Students' primary role becomes more important as external objective learning conditions become more prevalent. Teachers must guide students to closely follow the text and read, as well as use multimedia to expand reading, to prevent students from becoming lost in the vast amount of information available on the Internet. The preview content assigned by the teacher should be closely related to the text as an aid to classroom teaching, such as clearly pointing out where the text's background, author's life, and other people's comments on this article can be found. Students' learning concepts should change in tandem with the advancement of modern educational technology, from text reading to hypertext reading, from hand-drawn to hypertext structure conception and writing. The multimedia teaching process essentially aligns with people's cognitive processes from perceptual to rational, allowing students' perceptual processes to be accelerated and cognition and understanding to be deepened. However, some students may struggle to adjust to the significant increase in classroom teaching information. Then, students should work on honing their ability to process a large amount of data. We discovered that in the past, film projection was used to deliver all of the teaching content at once. Although the amount of information was increased, different students' attention was easily dispersed on different information, resulting in an outof-control small-scale teaching. Students can easily concentrate their attention by taking notes and thinking along with teachers' teaching ideas in traditional blackboard writing teaching, but the amount of information taught is relatively small. The research and practical application of multimedia teaching theory should be prioritized in schools. We should fully comprehend the multimedia teaching mode and make a greater breakthrough through continuous research against the backdrop of modern education and teaching theory.

Sustainability is the standard for judging the quality of teaching, transformation system, and subsystem. Based on the development speed of each subsystem:

$$
D_{i}=a+\sum_{j=1}^{n} b_{j} p_{j}+r_{i} Y+u
$$




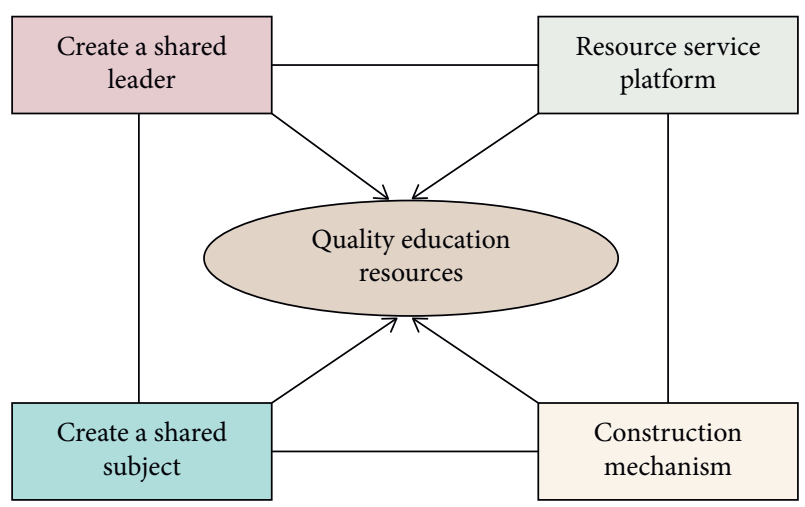

FIgURE 1: Educational resource sharing model.

Use clustering algorithm function method to find

$$
D_{i}=a+\sum_{j=1}^{n} b_{j} \ln \left(p_{j}\right)+r_{i} \ln (Y)+u \text {. }
$$

The calculated trend degree is

$$
\ln \left(D_{i}\right)=a+\sum_{j=1}^{n} b_{j} \ln \left(p_{j}\right)+r_{i} \ln (Y)+u
$$

The traditional reading teaching resources are mainly words, supplemented by pictures, tapes, and other devices that can help students understand. In the process of multimedia teaching, these single media forms are compounded, and other forms such as animation, video, online courses, and online study groups are added on this basis, which innovates the means of reading teaching and makes the flat teaching method three-dimensional and comprehensive. Feedback can help teachers know the students' learning attitudes and emotions, the students' acceptance of multimedia teaching methods, the students' learning achievements, and other information in time. Feedback provides the basis for teachers to adjust and control various teaching designs including teaching degree, teaching progress, and teaching methods.

4.2. Improve Students' Reading Enthusiasm. Creating problem situations and implementing heuristic teaching is one of the most stimulating conditions for learning motivation. Students can assimilate new knowledge by applying their existing knowledge and experience in a real-world setting. Multimedia teaching is the future development trend in education and teaching methods, and teaching quality will inevitably improve, with students being the primary beneficiaries. The main role of students becomes more important as the external objective conditions of learning become more important. All human activities are dominated by needs, motives, and interests, according to psychology studies. Students' learning concepts should change in lockstep with the advancement of modern educational technology, from text reading to hypertext reading, from hand-drawn to hypertext structure conception and writing. The multimedia teaching process is designed to align with people's cognitive processes as they progress from perceptual to rational, allowing students to accelerate their perceptual processes and deepen their cognition and understanding. The implementation process of mixed English reading teaching based on multimedia technology is shown in Figure 2.

Students should approach the challenges posed by modern educational technology with optimism. On one hand, teachers should avoid situations in which students do not consider searching for answers directly on the Internet, such as writing extracurricular reading exercises by themselves based on the current situation of students in our school, or exercises after class that are primarily open-ended questions. On the other hand, to maintain communication and interaction, it is necessary to provide timely feedback to questions raised by students in the online learning platform. The main goal of multimedia teaching is to increase teaching efficiency and quality, so that students who are learning subjects can achieve high levels of learning efficiency only by giving it their all. According to modern teaching philosophy, class time should be reduced, and more time should be set aside for students to practice and think. An effective multimedia teaching process can effectively reduce classroom teaching hours, provide more time and space for students to learn independently, and increase the degree of freedom for students to design their own learning experiences. Students can independently search for a large number of reading materials and find out what they are interested in with multimedia, as long as the teacher chooses the theme. As the contents chosen by each student may differ significantly, students may experience double or even multiple reading effects as a result of their communication. Figure 3 shows a path analysis model for the construction dimension and learning effect of the English reading teaching environment.

Set up indicators for teaching quality evaluation. Describe them as the following quantitative comprehensive evaluation matter-element models:

$$
\operatorname{CPV}(k)=\frac{\sum_{j=1}^{k} \lambda_{j}}{\sum_{j=1}^{m} \lambda_{j}} .
$$

The matter-element model formed by the allowable value range of each index in the comprehensive evaluation of teaching reform is called the node-domain matter-element:

$$
F_{i k}=\sum_{j=1}^{m} q_{j} x_{i j}
$$

Express the detected data or analysis results with matter elements:

$$
f(t)=\sum_{j=1}^{N} \sum_{k \in Z} d_{k}^{j} \phi_{j k}(t)+\sum_{k \in Z} c_{k}^{N} \phi_{N k}(t) .
$$

Use the weight coefficient of each feature to calculate the relevance of the teaching quality evaluation reform on the grade:

$$
E_{m i}=\sum_{i=1}^{k}(i \Delta t) \cdot\left|S_{m i}\right|^{2}
$$




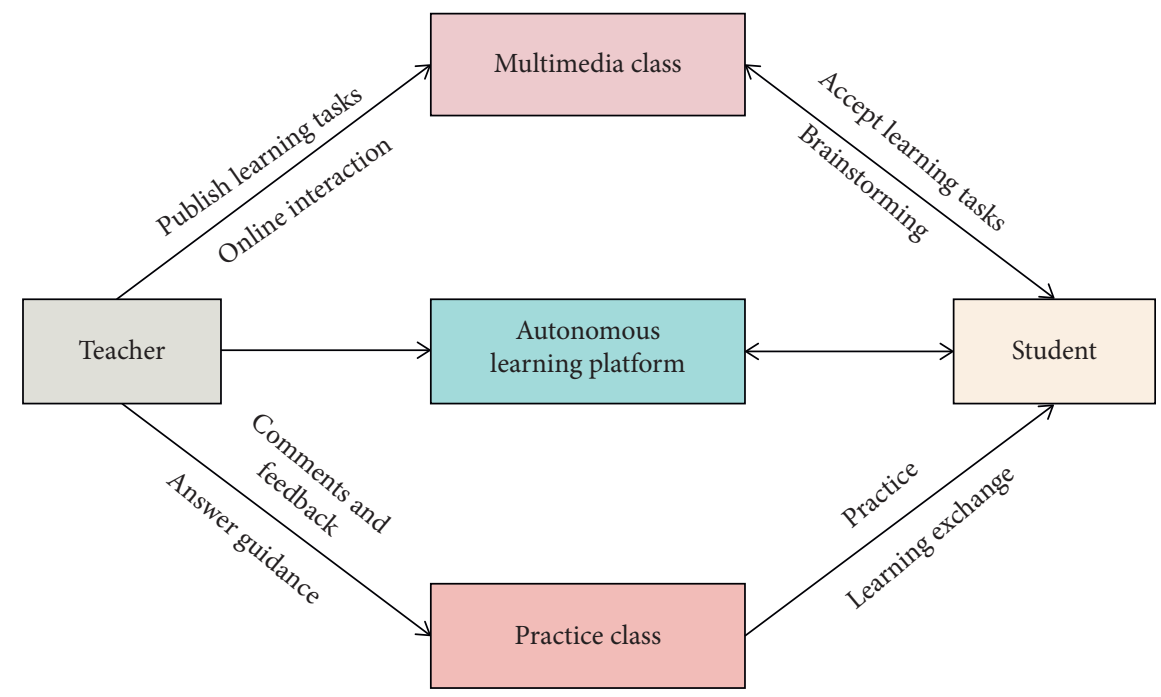

FIGURE 2: Blended English reading teaching.

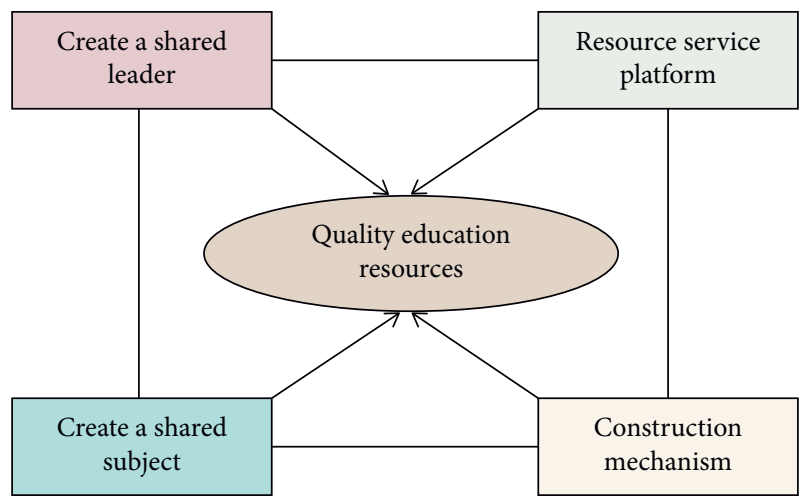

Figure 3: Path analysis model.

Students should actively cultivate their ability to acquire knowledge through various media in school so that they can continue to enrich and update their knowledge through various media once they leave school. Reading instruction can be made more orderly with the help of multimedia technology. Multimedia technology can assist teachers in providing reading instruction to students. Multimedia provides more possibilities for reading teaching as science and technology progress and teaching levels improve. Students can gain intuitive visual experience by transforming abstract images into concrete ones. Teachers can show students pictures of beautiful scenery during the course introduction to encourage students to love the motherland and nature when writing prose or poetry that depicts scenery. The primary goal of multimedia teaching is to increase teaching efficiency and quality, so that students who are learning subjects can achieve high levels of learning efficiency only by fully committing themselves.

\section{Result Analysis and Discussion}

Based on the teaching principle of constructivism, the teaching process is no longer a unilateral knowledge infusion, but the classroom is constructed by teachers and students. College English learning should create a real
English-learning environment for learners with the support of multimedia network technology. In the real Englishlearning environment, learners re-organize and transform their own knowledge and experience and actively construct meaning to acquire new knowledge. The design of multimedia CET resources should conform to students' cognitive development level and psychological development law and design and select college English-teaching resources based on a full understanding of students' cognitive level and interests.

After the parameters are adjusted, the data flow quickly reaches a steady state. The initial rotation is too large, which may result in excessive data flow. Perform three sets of data testing and statistical results, as shown in Figure 4.

The main evaluation object and criterion for judging students' reading effect is the traditional teacher of reading teaching evaluation. It can be said that when the teacher is absent, the evaluation process becomes more difficult. However, when using multimedia reading instruction, the appropriate teaching software can be preprogrammed. After class, students can complete reading exercises based on the software's prompts, checking pronunciation, words, text comprehension, and other factors. The software can also make a corresponding evaluation on students' answers and enter different links, which not only saves teachers a lot of time revising exercises and explaining basic concepts but also allows students to receive evaluation feedback quickly after completing the questions. It is possible to generate and collect big data in the classroom, and it is critical for teachers to fully explore and practice these data. The simulation of multimedia education teaching design is analyzed from various angles during the teaching stage, using multimedia technology. The experimental results of three experiments are shown in Figure 5.

According to constructivist teaching theory, students' language skills must be acquired through a process of meaning construction, and learning a language in a realworld setting is the most effective method. Students benefit from the use of teachers' multimedia technology to create a 


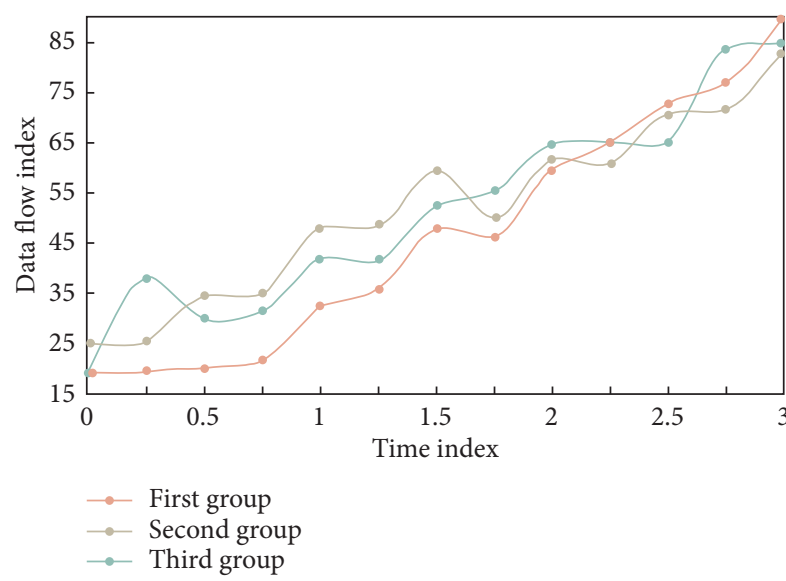

Figure 4: Data impact over time.

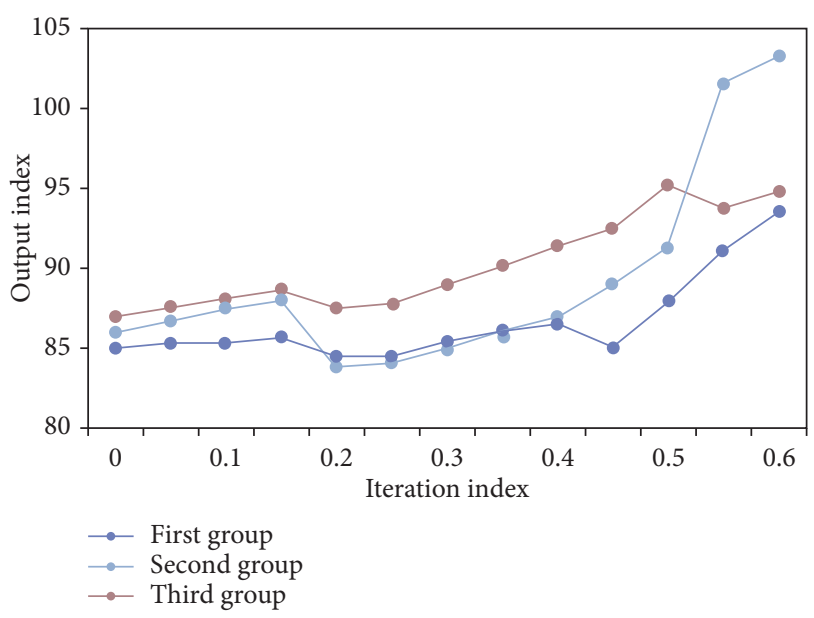

FIGURE 5: Iteration value and output relationship.

realistic learning environment. Students construct the meaning of knowledge and practice listening in this authentic language learning environment, which includes both visual and auditory stimuli. Multimedia teaching is an auxiliary teaching method in CET. Although multimedia technology can effectively improve the teaching effect in the classroom, teachers should still be in charge; multimedia technology can only serve as a technical auxiliary means for teachers to play the lead role. They can only assist teachers rather than replace them, and they cannot take over teaching responsibilities. A stage test should be conducted after the first stage of English reading instruction with multimedia is implemented. The test results serve as a foundation for not only evaluating students' learning effects at this stage but also for adjusting strategies at the next stage. The test results are shown in Figure 6.

According to the traditional way of reading evaluation, if teachers want to evaluate students' reading effect, they must do it in the classroom. However, using multimedia reading teaching and setting up an online learning platform, students can upload their collected reading materials and completed reading exercises to the platform, and teachers can give feedback immediately. For universal

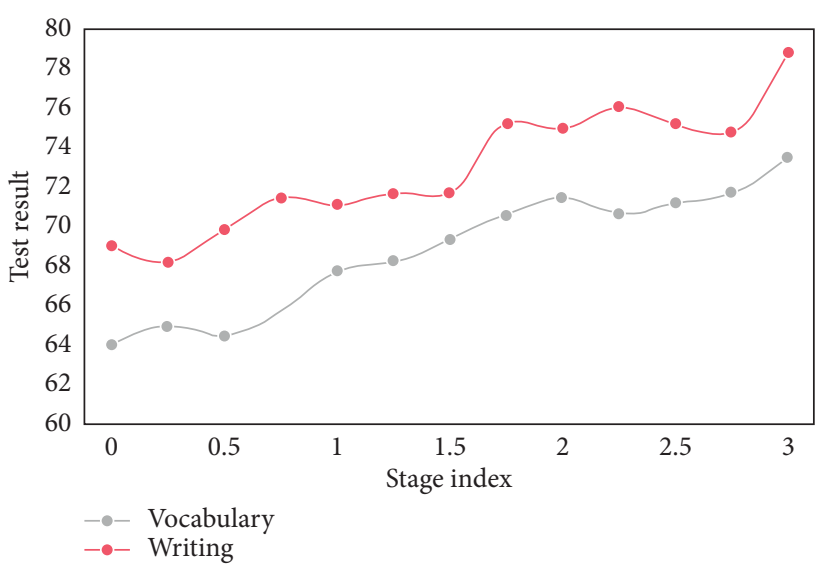

Figure 6: Comparison of achievements.

incomprehensible problems, teachers can also summarize them and re-emphasize them in class to deepen students' impression. Based on the developmental evaluation theory, multimedia-assisted CET resources must attach importance to the interest of the teaching process in the design process, so that students can experience the beauty of the teaching process, stimulate students' interest in learning and cultivate students' learning motivation. Teachers should inherit the essence of traditional methodology, seize the opportunity brought by modern IT revolution, give full play to the characteristics of traditional teaching methods and modern multimedia technology, complement each other, make full use of modern IT, such as multimedia and network, and promote the effective application of new teaching mode.

In CET, if the multimedia teaching system can be properly used to solve the audio-visual and other related teaching problems in English teaching, students can acquire basic English knowledge in a limited classroom, and at the same time, their basic language skills can be trained, thus achieving the real purpose of applying multimedia-assisted teaching system to CET. The results of the evaluation index parameters of reading teaching level can be regarded as the research object, and data clustering and information fusion are carried out. The evaluation results are shown in Figure 7.

The English proficiency test scores of the students in the experimental class and the control class were obtained, and the relevant data were statistically analyzed by statistical software. After the experiment, compare the class scores again. The results of the two classes before and after the experiment are compared as shown in Figure 8.

It shows that multimedia technology is of positive significance to improve college English prediction skills and reading efficiency. Using multimedia technology, teachers can also supervise and ask questions about students' learning progress through computers, communicate effectively with students and give timely feedback to students' learning results. Teachers can give students visual and auditory information through their own pronunciation, intonation, and expression, and then use the illustrated forms of multimedia to arouse their emotional resonance. With the support of multimedia technology, these advanced organizers are presented in the form of visual and dynamic images and videos, which changes the traditional 


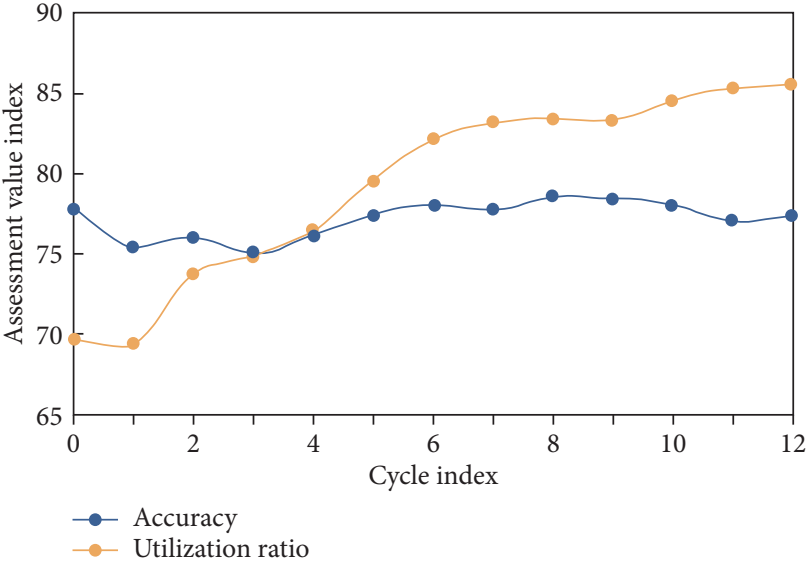

Figure 7: Evaluation test results.

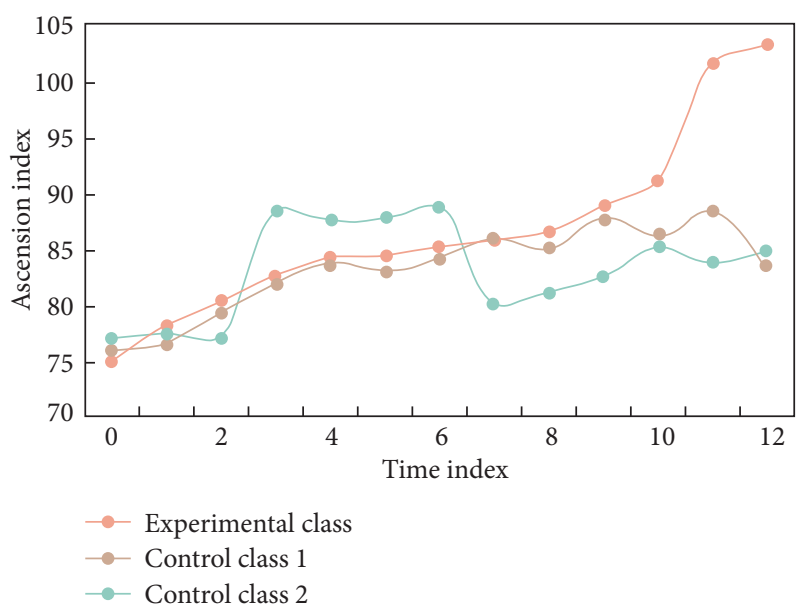

FIGURE 8: Comparison of results before and after the experiment.

presentation in the form of words and makes it easier for students to connect and integrate new and old knowledge, understand and master new knowledge in the process of learning new knowledge.

\section{Conclusions}

Education modernization is a widespread trend, but it must not become a form of zealous and blind pursuit. Instead, we should prioritize students' actual needs and implement multimedia instruction with the goal of improving students' reading efficiency. Improving the efficiency of reading instruction is not a simple task. The proper use of audio-visual media, on the contrary, has been demonstrated in practice to effectively stimulate students' learning subject consciousness, arouse their interest in learning, and achieve good teaching effect. Students construct the meaning of knowledge in this real-world learning environment using both visual and auditory stimuli, while teachers monitor students' learning progress and effect using multimedia-assisted teaching resources. The design of college English-assisted teaching resources should be based on the teaching principles of "student-centered, process-oriented, communication-oriented, and people-oriented," giving full play to the advantages of IT and multimedia resources in the educational information environment. We can only improve teaching efficiency and quality by organically combining multimedia technology, teachers' leading role, and students' main role. The breadth and depth of this study have some limitations, and some issues in the detailed explanation and discussion need to be investigated further in order to realize the optimization of college English classrooms in a multimedia technology environment.

\section{Data Availability}

The data used to support the findings of this study are included within the article.

\section{Conflicts of Interest}

The authors declare no conflicts of interest.

\section{References}

[1] A. El Saddik, "Digital twins: the convergence of multimedia technologies," IEEE multimedia, vol. 25, no. 2, pp. 87-92, 2018.

[2] M. D. Abdulrahaman, N. Faruk, A. A. Oloyede et al., "Multimedia tools in the teaching and learning processes: a systematic review," Heliyon, vol. 6, no. 11, Article ID e05312, 2020.

[3] U. Murod, B. Suvankulov, M. Bakiyeva, and D. Nusratova, "Fundamentals of creation and use of interactive electronic courses on the basis of multimedia technologies," Annals of the Romanian Society for Cell Biology, vol. 25, pp. 6860-6865, 2021.

[4] K.-E. Kim, J. E. Jung, Y. Lee, and D. S. Lee, "Ranking surface soil pollution potential of chemicals from accidental release by using two indicators calculated with a multimedia model (SoilPCA)," Ecological Indicators, vol. 85, no. 2, pp. 664-673, 2018.

[5] M. Torres and G. Qiu, "Habitat image annotation with lowlevel features, medium-level knowledge and location information," Multimedia Systems, vol. 22, no. 6, pp. 1-16, 2016.

[6] S. Craciun, R. Kirchgessner, A. D. George, H. Lam, and J. C. Principe, "A real-time, power-efficient architecture for mean-shift image segmentation," Journal of Real-Time Image Processing, vol. 14, no. 2, pp. 379-394, 2018.

[7] D. X. Xia, S. Z. Su, L. C. Geng, G. X. Wu, and S. Z. Li, "Learning rich features from objectness estimation for human lying-pose detection," Multimedia Systems, vol. 23, no. 4, pp. 1-12, 2016.

[8] M. Li, E. Geva, N. D’Angelo, P. W. Koh, X. Chen, and A. Gottardo, "Exploring sources of poor reading comprehension in English language learners," Annals of Dyslexia, vol. 71, no. 2, pp. 299-321, 2021.

[9] Y. T. Hsiao, R. Shillcock, M. Obregón, H Kreiner, M. A. J Roberts, and S McDonald, "Differential vergence movements in reading Chinese and English: greater fixationinitial binocular disparity is advantageous in reading the denser orthography," Quarterly Journal of Experimental Psychology, vol. 71, pp. 1-33, 2017.

[10] J. Lin, Y. H. Lee, D. Y. Wang, and S. J. Sunny, "Reading subtitles and taking enotes while learning scientific materials in a multimedia environment: cognitive load perspectives on 
EFL students," Educational Technology \& Society, vol. 19, 2016.

[11] F. Amadieu, J. Lemarié, and A. Tricot, "How may multimedia and hypertext documents support deep processing for learning?" Psychologie Française, vol. 62, no. 3, pp. 209-221, 2017.

[12] D. Jiang, W. A. Renandya, and L. J. Zhang, "Evaluating ELT multimedia courseware from the perspective of cognitive theory of multimedia learning," Computer Assisted Language Learning, vol. 30, no. 5-8, pp. 726-744, 2017.

[13] E. Herakleioti and P. Pantidos, "The contribution of the human body in young children's explanations about shadow formation," Research in Science Education, vol. 46, no. 1, pp. 21-42, 2016.

[14] H. Changyu, "Using multimedia technology to optimize English reading teaching in junior high schools," Navigation in Arts and Science: Educational Research and Practice, vol. 10, no. 10, p. 2, 2017.

[15] $\mathrm{L} . \mathrm{Hu}$, "On the role of multimedia in the cultivation of core literacy in high school English reading teaching," Campus English, vol. 32, no. 32, p. 2, 2017.

[16] M. J. Kieffer, J. Mancilla-Martinez, and J. K. Logan, "Executive functions and English reading comprehension growth in Spanish-English bilingual adolescents," Journal of Applied Developmental Psychology, vol. 73, no. 3, Article ID 101238, 2021.

[17] W. Bai, "The effective use of multimedia teaching in high school English reading under the background of "Internet+"," Times Education, vol. 18, no. 18, p. 1, 2016.

[18] B. Yao and C. Scheepers, "Direct speech quotations promote low relative-clause attachment in silent reading of English," Cognition, vol. 176, pp. 248-254, 2018.

[19] C. Ma, "A brief analysis of the application of multimedia in English reading teaching in junior high schools," Curriculum Education Research: Study of Learning Method and Teaching Method, vol. 13, no. 13, p. 1, 2016.

[20] C. P. Proctor, D. August, M. S. Carlo, and E. S. Catherine, "The intriguing role of Spanish language vocabulary knowledge in predicting English reading comprehension," Journal of Educational Psychology, vol. 98, no. 1, pp. 159-169, 2016.

[21] C. Richards-Tutor, D. L. Baker, R. Gersten, S. K. Baker, and J. M. Smith, "The effectiveness of reading interventions for English learners," Exceptional Children, vol. 82, no. 2, pp. 144-169, 2016.

[22] S. You, M. Dang, and S. A. Lim, "Effects of student perceptions of teachers' motivational behavior on reading, English, and mathematics achievement: the mediating role of domain specific self-efficacy and intrinsic motivation," Child and Youth Care Forum, vol. 45, no. 2, pp. 221-240, 2016.

[23] A. Gottardo, N. Amin, A. Amin, R. Al-Janaideh, X. Chen, and J. Paradis, "Word reading in English and Arabic in children who are Syrian refugees," Applied PsychoLinguistics, vol. 41, no. 6, pp. 1305-1328, 2020.

[24] F. Ma and H. Ai, "Chinese learners of English see Chinese words when reading English words," Journal of Psycholinguistic Research, vol. 47, no. 4, pp. 505-521, 2018.

[25] H. L. Swanson, "A latent transition analysis of English learners with reading disabilities," Topics in Language Disorders, vol. 37, no. 2, pp. 114-135, 2017.

[26] K. Alhazmi, J. Milton, and S. Johnston, "Examining "vowel blindness" among native Arabic speakers reading English words from the perspective of eye-tracking," System, vol. 80, pp. 235-245, 2019.

[27] I.-F. Liu and S. C. Y. Shelley, "An exploration of participative motivations in a community-based online English extensive reading contest with respect to gender difference," Interactive Learning Environments, vol. 25, no. 1/4, pp. 48-61, 2017. 